\title{
Identity disclosure as a securityscape for LGBT people
}

\section{Nurbek Omurov}

Psychology Department, American University of Central Asia (AUCA), Bishkek, Kyrgyzstan

Corresponding author. E-mail: nkomurov@gmail.com

Background. The concept of a securityscape is an emerging approach to understanding human (in)securities. It derives from the concept of scapes that was initially proposed by anthropologist and cultural theorist Arjun Appadurai in 1996. Securityscapes are imagined individual perceptions of safety motivated by existential contingencies or otherwise theorized as givens of existence, according to psychotherapist Irvin Yalom: death, freedom, existential isolation, and meaningfulness. A recent study on securityscapes in Kyrgyzstan and Tajikistan described different securityscapes among selected socially and politically vulnerable communities, including the LGBT community. It listed securityscapes of LGBT people but did not provide details as to how such securityscapes are formed. Disclosure of a stigmatized identity was one such securityscape.

Objective. This article elaborates on research on how LGBT people consider disclosure of their stigmatized identity a securityscape.

Design. This study was conducted using a semistructured biographical interview with LGBT people in Kyrgyzstan.

Results. It found that both voluntary identity disclosure and the decision to conceal the stigmatized identity are considered contrasting securityscapes by LGBT people, depending on how central the stigmatized identity is to their self-conception.

Conclusion. The study concludes that identity disclosure as a securityscape should be considered on a continuum, with identity concealment as a securityscape on one end and complete identity disclosure as a securityscape on the other.

Keywords: LGBT, securityscape, stigmatized identity, identity disclosure, givens of existence

\section{Introduction}

The article is based on research that was conducted on the concept of securityscapes shaped by existential threats, with particular attention to identity disclosure as a securityscape for LGBT people. I consider proactive and voluntary disclosure of a stigmatized identity as a security-making and analyze how identity disclosure as a securityscape is pursued by LGBT people in a nonaffirming environment (so- 
cieties in which LGBT people are stigmatized and discriminated against) within the givens of existence, as theorized by Yalom.

An emerging theory of securityscapes derives from the concept of scapes, which was introduced by anthropologist and cultural theorist Arjun Appadurai in 1996 in his book Modernity at Large: Cultural Dimensions of Globalization, wherein he described how globalization had been evolving and how it had influenced modern life across the world. He described the world today as a place where people from different countries, cultures, and backgrounds move and interact; it is where ideas and technology are shared and exchanged, along with individual perceptions of the imagined. By describing all of the above as "global cultural flows," Appadurai developed a theory around them and framed it as a concept of scapes. He believed that migration, development of technology, and exchange of finances and ideas were catalysts of globalization that detached people from their geographical locations, allowing them to imagine their boundaries beyond the physical ones.

Based on the above, Appadurai (1996) framed the following five scapes: (1) ethnoscapes: when people migrate to other countries, bringing their own cultures as well as adopting the cultures of host countries; (2) mediascapes: modern communication technologies that quickly allow the sharing of localized information globally, as well as how media changes people's imaginations and perceptions; (3) technoscapes: wherein emerging technologies originating in one place can quickly spread throughout the world, influencing people's everyday lives; (4) financescapes: the exchange of currencies, stocks, and related commodities; and (5) ideoscapes: wherein ideologies of different countries and cultures influence each other, changing the political and ideological beliefs of people. Therefore, Appadurai defines scapes as imagined perceptions of ethnic, cultural, religious, national, political, and other identities not bound to geographical or communal boundaries but rather influenced by catalysts of globalization, such as migration, technology, media, and ideology. Another important conclusion made by Appadurai regarding these scapes is that they are also very individual, depending on where people live, where they move, what technologies they use, and what they believe in.

Following Appadurai's concept of scapes, von Boemcken et al. (2016) introduced the "concept of securityscapes" (p. 5), similarly reasoning it as Appadurai theorized his scapes, and describing security from a human agency perspective. They investigated securityscapes as "not necessarily de-territorialized imagination," arguing that "securityscapes do involve borders and boundaries" (p. 7). The concept of securityscapes can be best understood by looking back at how discussions about security have evolved historically.

Although security as a concept and approach has been thoroughly researched, the majority of work has focused on conventional perceptions of security, exploring it from a "state-centric" approach (von Boemcken et al., 2016, p. 5), and from a geopolitical focus within an international relations prism (Wilson \& Bakker, 2016). However, recent research has attempted to scrutinize security from various perspectives, for example: a concept of human (in)security as proposed by the United Nations Development Program (Human Development Report, 1994). The report introduced the concept and urged the international community to change its perspective on security and start focusing on everyday measures people undertake in order to ensure their safety. And even at that, human security was researched from 
a top-down perspective again, failing to explore how human (in)securities form (Lemanski, 2012). Despite all these efforts to explore security from different angles, the majority of them continued overlooking how security is "experienced, felt, and managed by people" (Crawford \& Hutchinson, 2015, p. 3).

Summarizing discussions and debates that have taken place around the topic of understanding security from a non-state-centric perspective, von Boemcken et al. (2016) attempted to define securityscapes as "security-related imaginations and practices" (p. 17). According to these authors, people in their everyday lives tend to respond to existential threats by imagining potential solutions. They do so by mapping and picturing secure and safe environments (both psychosocial and geographical-spatial) for themselves, and adjusting their attitudes and behavior (whether conscious or subconscious) to fit within their imagined secure worlds.

Von Boemcken et al. (2016) described the concept of how the securityscapes of marginalized groups is pronounced and adopted due to their stigmatized and underprivileged status. The research was conceptualized in 2015 and conducted in 2016 among selected marginalized communities of Kyrgyzstan and Tajikistan, including the lesbian, gay, bisexual, transgender (LGBT community) in the Kyrgyz capital of Bishkek. Preliminary findings show that each of these marginalized communities practice securityscapes particular to their realities facing various the "existential contingencies of life" (p. 7). However, in their working paper, von Boemcken et al. did not break down these contingencies.

According to Yalom, there are four givens of existence around which humans shape their behavior: death, freedom, existential isolation, and meaningfulness (1980). Each of these threats shapes our behavior and how we live our lives: when we choose our homes, the neighborhoods we live in, our friends and social circles, the education we pursue, the jobs we undertake, etc. Death is the first given of existence. Humans are always aware of death, from childhood throughout their entire lives, and fear of death makes us adopt different avoidance or denial strategies. Similar to Yalom's description of death as an existential threat, the philosopher Rosenzweig also claimed that people are constantly reminded about the inevitability of death and therefore "it is death which makes us human" (Goldstein, 2015). The second given according to Yalom (2013, 3ed., p. 7) is freedom and our will to live our lives as we wish and find comfort. Existential isolation is the third given of existence theorized by Yalom (p. 10). People are afraid of loneliness; they seek out social interaction, attention, and a feeling of belonging. And finally, Yalom discusses meaningfulness as the fourth given of existence (p. 12), which claims that people tend to seek answers to questions such as "what" and "why": What is the meaning of their lives? What is the purpose of life? What is their role in life? Why were they born? If one does not find answers to these questions, one tends to live in continued distress, leading to severe psychological disorders.

In this article I take the concept of securityscapes shaped by existential threats and focus particularly on identity disclosure as one of the securityscapes for LGBT people. I consider proactive disclosure of a stigmatized identity as an imagined security-making by LGBT people and analyze how identity disclosure as a securityscape is pursued by LGBT people in a nonaffirming environment (societies in which LGBT people are stigmatized and discriminated against). 
From a psychological perspective, counseling people who identify as LGBT in nonaffirming societies remains a significant challenge in a general population that is not accepting of LGBT identities, but rather only heterosexual orientation and cisgender binary (used to describe a person whose gender identity and gender expression align with the sex they were assigned at birth) (APA, 2015). This heteronormative assumption prizes heterosexuality as natural, normal, and right. This mindset further feeds the existing patriarchal system, enabling state- and nonstate-funded discrimination against people who do not fall within the behavioral norms generally accepted in the society (Costa, Pereira, \& Leal, 2013). Constantly facing stigmatization and systematic discrimination, people with an invisible stigmatized identity continue living in isolation and loneliness (Bristol City Council Report, 2014), with pronounced "internalized homonegativity" (Frost \& Meyer, 2009) caused by cognitive dissonance when there is a conflict between identities within one's self-conception (Barnes \& Meyer, 2012).

Kyrgyzstan, where the subject of this article was researched, is a country nonaffirming of LGBT people despite the fact that the legislative framework has decriminalized them in terms of allowing people to express their sexual orientation and gender identities. However, LGBT identities in Kyrgyzstan are frowned upon and generally unwelcome. At the decision-making and policy-formation levels, LGBT issues are ignored; moreover, it is even openly condemned by politicians and toplevel government officials. Hate speech toward LGBT persons is not prosecuted, and cases are often left untried. Political groups and conservative movements openly attacking LGBT people and publicly calling for violence are tolerated and even encouraged without any legal repercussions. Public opinion is manipulated by the government, which maintains and even nurtures existing prejudices about LGBT people, resulting in abuse of and discrimination against LGBT people (Universal Periodic Review, 2014). This environment may make it even more complicated for LGBT people to psychologically find acceptance of their sexual orientation and/or gender identity. However, LGBT people's consideration of disclosing their stigmatized identity as a securityscape, especially under such sociopolitical and cultural circumstances as exist in Kyrgyzstan, suggests that LGBT identity disclosure is twofold.

Cass (1979), one of the pioneers in the field of identity disclosure by LGBT people, proposed a six-stage identity formation model of people who identify as homosexual: (1) identity confusion: when a homosexual person compares self-perceptions of sexual orientation as nonconforming to societal norms and expectations; (2) identity comparison: when a homosexual person starts exploring the identity in question while at the same time trying to conceal it; (3) identity tolerance: when a homosexual person comes somewhat into terms with his/her sexual orientation and starts seeking out similar others; (4) identity acceptance: when homosexual identity is either kept private within a close circle of social interaction or can be disclosed to the public; (5) identity pride: commitment to own sexual orientation and taking pride in it, when a person strongly conflicts with heteronormativity as something jeopardizing his/her existence; and (6) identity synthesis: at which stage a homosexual person is in full harmony with his/her own sexual orientation, accepting of heterosexual people who express understanding, and no longer considers homosexuality as their only identity. At this final stage, according to Cass, 
a person considers oneself a "synthesis" of several identities. Although this model attempts to illustrate the process of identity formation of homosexual people, it is very linear and fails to consider many external factors.

According to the review by Bilodeau \& Renn (2005), they discussed how identities attached to other sexual orientations are experienced. By analyzing bisexuality, the authors described how bisexual people experience their understanding of their sexual orientation. The review provides an insight into how bisexual people first identify as homosexuals, or live as heterosexuals prior to identifying as bisexuals. Other bisexual people claim to have identified as such since their childhood, which is also very legitimate. What is interesting to compare though, is that similarly to cisgender bisexual people, men and women who identify as transgender also have different ways of understanding their sexual orientations.

Although much research on LGBT identity disclosure describes the process in general, assuming that decisions about identity disclosure are similar among all representatives of the LGBT community, it has failed to investigate unique factors important to transgender people. They, unlike cisgender people, have two stigmatized identities: their sexual orientation, if it is nonheterosexual, and their gender identity, which does not conform to their sex assigned at birth. Therefore, transgender people's identity disclosure is more complex than that of cisgender LGB people (Zimman, 2009). Transgender people at the stage of adolescence struggle with gender identity and sexual orientation issues. According to Zimman (2009), they often initially disclose their identity as gay or lesbian (usually due to trying to make sense of their feelings of difference and access to LGB identities); later, when they proceed with gender reassignment, their confusion about "perceived homosexual identity" may decrease. However, if transgender people also identify as gay, lesbian, bisexual, or any other nonheterosexual orientation, then they face stigma even after their transition (APA, 2011).

Another difference between the stigmatized identities of transgender and cisgender LGB people lies in the visibility or invisibility of the stigmatized identity. For cisgender LGB people, their sexual orientation is usually invisible to others, whereas for transgender people, their gender identity may become visible during a stage of their transition or immediately afterwards, leaving them visible, and thus disclosure loses its relevance. Zimman (2009, p. 60) proposes two distinguishing terms to describe the main disclosure stages of transgender identity: "declaration," when transgender people declare their real identity, and "disclosure," when transgender people decide to disclose their past identity. Declaration can be either verbal and intentional, or nonverbal (and intentional or unintentional).

So why do LGBT people disclose their stigmatized identity? Self-disclosure of a stigmatized identity is an "act of making yourself manifest, showing yourself so others can perceive you" (Chaudoir \& Fisher, 2010, p. 5). As was mentioned earlier, "concealed" identity puts psychological pressure on LGBT people; they carry the burden of their stigmatized identity regardless of where they are: at work, at home, or among friends (Ragins, 2008, Chaudoir \& Fisher, 2010). The continued anxiety and stress that result from persistent thoughts of determining whether to disclose or not, the adoption of various strategies to avoid discussions that could remotely relate to sexual orientation and/or gender identity, and pretending to be someone 
else all their toll on the psychological well-being and health of any LGBT person (Chaudoir \& Fisher, 2010).

Studies on stigmatized identity disclosure have thoroughly discussed theories around stigma. They define stigma as labels associated with certain identities of individuals that do not fall within socially accepted norms, resulting in prejudice, social judgment, and discrimination (Ragins, 2008). According to one study, a decision to disclose a stigmatized identity is dependent on the "antecedents" (p. 198) or external and internalized challenges that LGBT people face when making the decision.

Therefore, to understand the disclosure process and the reasoning behind it, Ragins (2008) classified "three antecedents: self-verification and centrality of the identity, anticipated consequences associated with the disclosure, and environmental support" (p. 198). The centrality of the self-conception of who a person is to his or her identity is vital in the decision about disclosure. LGBT people, besides attributing their identity to their sexual orientation and gender, may hold other identities, including a religious one, which, in the majority of cases, may conflict with their LGBT identity. Depending on whether these identities are central to the person's self-conception, an LGBT person will or will not disclose their sexual orientation and/or gender identity. Another antecedent is whether an LGBT person feels social support for his or her stigmatized identity, that is, if the social environment is welcoming and accepting of LGBT identities or not. Finally, the third antecedent is environmental support, that is, when an LGBT person is either surrounded with supportive non-LGBT people or other LGBT people, and if there is institutional support, such as LGBT movements or organizations, politicians publicly defending LGBT people, etc. If all of these three antecedents are conducive to identity disclosure, the self-conception of an LGBT person will be central to their identity and they will be more likely to disclose their identity. In this regard, Chaudoir \& Fisher (2010) complement Ragin's discussion about antecedents by proposing antecedent motivations such as "approach motivation and avoidance motivation" ( $p$. 6). Approach motivation leads to expecting a desired outcome of acceptance and inclusivity, further resulting in personal psychological benefit (finding harmony with oneself and acceptance of one's own identity); this is otherwise described by Chaudoir \& Fisher as "alleviation of inhibition" (p. 3). As for avoidance motivation, it is in contrast to approach motivation and leads to anticipation of a negative outcome, such as rejection and even retaliation, in which case the decision will be to continue concealing one's stigmatized identity.

There are also a sufficient number of studies analyzing the consequences of identity disclosure and different scenarios. In research based on biographical interviews with women in sexual relationships with other women in Russia, various outcomes of lesbian identity disclosure were discussed. It also described scenarios in different domains, such as family, friends, coworkers, classmates, and healthcare workers, gynecologists in particular (Parfyonova, 2010). The findings of this study align with antecedents of stigmatized identity disclosure discussed above and demonstrate that all factors have their role in the "disclosure process model" (Chaudoir \& Fisher, 2010, p. 3).

Summarizing the findings of the research in the field of stigmatized identity disclosure, I have developed the following diagram demonstrating the process of 
stigmatized identity disclosure. It echoes Cass's six-stage identity formation model, Ragin's discussions about the continuum nature of the stigmatized identity disclosure process, and Chaudoir's and Fisher's stigmatized identity disclosure process model. I present it in a form of a "never-ending" circular funnel due to the fact that once an LGBT person discloses his or her sexual orientation or gender identity, it usually starts with a small circle of people (social surrounding), and it is an irrevocable process leading to further disclosures as the circle widens. LGBT people are always in a dilemma whether to disclose or conceal their identity every time they are in a new circle, so the stages of doubt and disclosure with feedback may occur over and over.

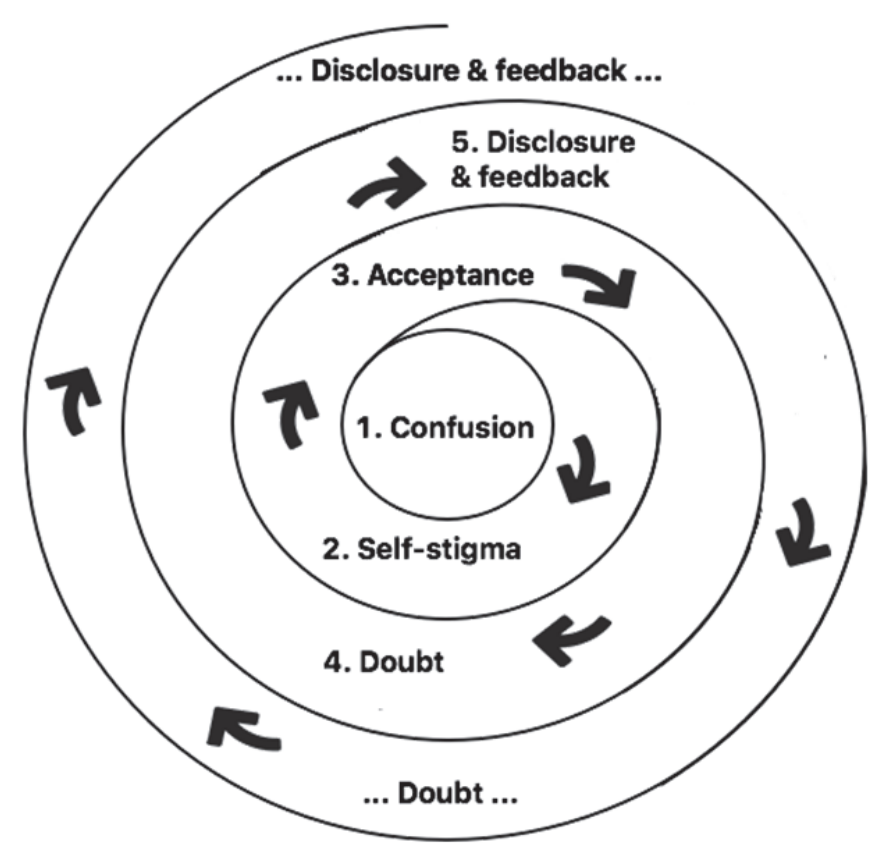

Figure 1. Disclosure process of invisible stigmatized identity disclosure by LGBT people

\section{Method}

\section{Research goal, hypotheses, and research questions}

Research goal. Theoretical reflections about the securityscape of stigmatized identity disclosure among LGBT people should be of use to psychological counselors in understanding human agency around sexual orientation and gender identity, and help these counselors obtain theoretical knowledge to respond to the psychological narratives of LGBT people who are contemplating disclosing their stigmatized identity. Therefore, the research goal is to investigate stigmatized identity disclosure by LGBT people as a securityscape in relation to existential threats.

Research hypotheses. The working paper by von Boemcken et al. (2016) investigating security-making and securityscapes targeted several marginalized 
communities in Kyrgyzstan and Tajikistan; one of the groups under investigation was LGBT people in the Kyrgyz capital, Bishkek. When researchers found numerous securityscapes described by subjects in the LGBT group, they assumed that proactive and voluntary disclosure of stigmatized identity was one of the securityscapes. However, the research did not explore this securityscape separately from others. My research examined two hypotheses. The first hypothesis stated that LGBT people deliberately and voluntarily disclose their sexual orientation and gender identity as a securityscape to safeguard themselves from existential threats. And the second hypothesis stated that the decision by LGBT people not to disclose their stigmatized identity and live their lives conforming to heteronormative standards is a securityscape in contrast to the identity disclosure securityscape.

Research question. This research sought an answer to the following research question: Is self-disclosure by LGBT people experienced as a securityscape, and if so, is it related to existential threats that support the disclosure as opposed to pressures to not disclose?

\section{Research location}

The research was conducted in the large cities of Bishkek and Osh in Kyrgyzstan, since they are relatively liberal toward LGBT people and host major human rights organizations providing outreach to research subjects. Interviews were conducted on the premises of these organizations and in community centers. Research findings were also influenced by aggregated and codified data collected from discussions organized for LGBT community members who attended the organizations' community offices where I conducted group interviews.

\section{Participants}

When I enrolled in a master's program, I started my internship at one of the LGBT organizations to gain access to research subjects. I conducted individual counseling and group therapy for LGBT people in line with my studies under supervision and built trust with both employees of LGBT organizations and visitors to LGBT community centers. The participants were people who identify as LGBT. They were informed about the goal and content of the research, and that it would be about the topic of identity disclosure by LGBT people. All the participants provided their consent to participate. When describing the research to them, I deliberately avoided using the words "security" and "securityscape," so they would not focus on the concept of security. However, the concept of scapes and securityscapes was explained to each participant upon completion of the interview.

The following factors were inclusion criteria:

(1) LGBT people 18 years and older: Due to societal limitations, it was decided not to recruit LGBT children for two obvious reasons. First, none of the LGBT organizations serve LGBT children due to security reasons, explaining that if their parents were to find out, they would retaliate against the organizations and jeopardize all their operations. Second, it would be difficult to obtain consent forms from the parents of LGBT children due to the 
specificity of the research topic and the stigma attached to LGBT issues in Kyrgyzstan.

(2) LGBT people who have voluntarily disclosed their identities: This was vital to learn about the experiences of LGBT people whose identities are no longer concealed or are partially concealed (according to the research hypothesis). The research targeted learning disclosure experiences within the securityscape concept of those who have publicly disclosed their identity, including to their friends, relatives, coworkers, or classmates (LGBT activists). The study also included LGBT people who have partially disclosed their identities to a limited circle of people; these respondents would describe different experiences, and their motivations for disclosing their identities to a limited number of people would uncover different dynamics.

(3) LGBT people who had not disclosed their sexual orientation and/or gender identity but were either planning to disclose in the future or did not consider disclosure as an option at all: According to the research hypothesis, the securityscapes of closeted LGBT people would significantly differ from those who have disclosed their identity. In addition, I anticipated that comparing the securityscapes of these two different groups could aid me in understanding proactive and voluntary identity disclosure as a securityscape among LGBT people.

Since there were very few LGBT people who had proactively and voluntarily disclosed their sexual orientation and gender identity and agreed to participate in the research, the following participants were interviewed: (1) a cisgender bisexual man who has not disclosed his sexual orientation and does not plan to disclose anytime in the future; (2) a cisgender homosexual man who has partially disclosed his homosexuality but maintains silence with his relatives, community members, and coworkers, and lives a heteronormative life; (3) a cisgender homosexual man who has partially disclosed his sexual orientation and lives accordingly; (4) a transgender bisexual man who has disclosed his gender identity but plans to conceal his past once his transition is completed; (5) a transgender bisexual man who has proactively and voluntarily disclosed his sexual orientation and gender identity, and who openly advocates for LGBT rights as a transgender person; and (6) a cisgender bisexual woman who has partially disclosed her sexual orientation to her relatives and considers becoming an advocate for the rights of bisexual people.

All these participants, except for one, were reached through LGBT organizations in Bishkek and Osh either via personal contact or through the social and outreach workers of the LGBT organizations. Out of the group that I attempted to recruit via a dating website, one person agreed to participate in the research. Moreover, it was important to ensure that all subgroups of the LGBT community are represented by at least one representative to see universal perceptions, similarities, and differences of identity disclosure as a securityscape across the subgroups.

\section{Design and procedures}

The research was conducted using a qualitative method based on semistructured biographical interviews with representatives of the LGBT community. The interviews 
revolved around stories of how the LGBT respondents understood and became aware of their differences as they grew into adulthood, and how they shared stories about their life prior to their sexual orientation and/or gender identity disclosure and after the disclosure to their confidants. Mainly storytelling and opinion- and thought-provoking questions were asked (Dunn, 2015), using the Rogerian approach of reflection and empathy to create an environment that allowed respondents to feel comfortable, open up, and reveal emotional and personal details of their lives (Rogers \& Kramer, 1995).

Universal guiding questions posed to respondents concerned the following: (1) becoming aware of one's own sexual orientation and gender identity; (2) the meaning of and importance for the person to disclose their stigmatized identity; and (3) life prior to and after the disclosure event.

The research also included those LGBT people who do not plan to disclose their sexual orientation and/or gender identity, who consider identity disclosure unnecessary and wished to keep their sexual orientation and/or gender identity personal. Interviews with this group of respondents was guided by the following two topics: (1) becoming aware of one's own sexual orientation and gender identity; (2) the meaning and importance for the person to disclose their stigmatized gender identity; and (3) strategies for avoiding or confronting "uncomfortable questions" (or heterocentric and heteronormative questions), by which I meant common questions that LGBT people are confronted with in a heteronormative environment, such as: (1) How do you get away when your friends start talking about sexual relations with the opposite sex? (2) What do you say when your relatives ask if you have a girlfriend/boyfriend? and (3) What is your regular response when your relatives put pressure on you about marriage? Also, when respondents used phrases such as "I should get married to a person of opposite sex," I asked a question such as: Tell me why you believe you should get married to a person of the opposite sex?

These were illustrative guiding clusters of questions, and each cluster was followed by various clarifications and other questions, depending on how the conversation evolved with each respondent.

When analyzing the findings of the research, I structured them following the four givens of existence to better display the results: death (fear of death), freedom, meaningfulness, and isolation. However, it is important to note that antecedents to disclosure and imagining identity disclosure as a securityscape can be motivated by a combination of these existential factors.

\section{Results}

\section{Disclosing stigmatized identity as securityscape to be free}

Disclosing stigmatized identity as a securityscape can best be illustrated by some of the reasoning the respondents provided based on their experiences. For transgender people who participated in this research, it was important to achieve independence in expressing who they are and living their lives freely in accordance with the identity they associate with. In security-making and disclosing one's stigmatized identity as a securityscape, first of all, social norms are challenged. One of the instruments to challenge societal norms is clothing styles and using fashion as 
a securityscape. For Azat, a 27-year-old transgender man, identity disclosure was indeed a securityscape; for him, it could only be achieved by making his invisible stigmatized identity visible to the maximum extent possible. He was trying to live his life to the fullest, and in his perception, he could achieve freedom and provide meaning to his identity by displaying it by means of his clothing style:

... And I, frankly speaking, wanted so much to show with all my appearance, meaning ... for example my hairdo, they were always different: all kinds of Mohawk[s], different hairstyles. I put on very bright clothes which was entirely different from what girls wore. I never had dark long hair, no black clothes or dark colors. All I put on was yellow, green, or something like that. And I wanted all the time ... I was so proud that I wanted to show with all my appearance that I love myself and am proud of myself.

Besides his looks, Azat also stated that in his human rights activism, his gender identity is very political. By discussing his gender identity publicly, a transgender activist is imagining a world where he can live free and have a safe life. Therefore, he publicly discloses his stigmatized identity as a security-making and is ready to assume responsibility for the results of the disclosure event:

Interviewer: I want to know: you have named so many identities, I was wondering, how different are they for you?

Azat: Oh yes. They are different, because if I say as a son, it is as such [one identity]. But there are certain qualities, that ... well ... can be described. If one says as a friend, there is loyalty, more emotional. As a partner-also different, as a colleague, as an activist also different in general, because when I say as an activist, for example, my transgender identity, for example, is political. I believe it to be important to underline this, whereas as an acquaintance, a [passer-by] on the street, I don't think [about] talking about it.

This is an example of how a transgender activist justifies the decision to disclose his gender identity and be vocal about it. A curious phrase is how he frames his transgender activism: "my gender identity is political." This phrase parallels a TV show in which a Byelorussian stand-up comedian disclosed his homosexuality during his performance (Zalutskii, 2017). His stand-up performance was built around his sexual orientation, the stage, and his performance, which are his security-making strategies similar to that of the transgender activist Azat, whose "stages" are conferences, meetings, and squares where he talks on behalf of transgender people and joins demonstrations, openly declaring his identity and support for transgender activism. These are some evidences to support the argument that being visible and vocal about a stigmatized identity is also a securityscape to safeguard oneself from physical injury and potentially from death when LGBT people are blackmailed and threatened for their identity (Human Rights Watch, 2014).

However, as I will discuss in detail later in the article, one could justly argue with the conclusion above by claiming that an opposite securityscape of being invisible is also a way to avoid physical harm and death. This ambivalent nature of securityscapes is very natural, because security-making and defining one's own securityscape vary by individual. And this is the concept of security-making I explore and question, contradicting conventional approaches to the understanding 
of security. In societies where LGBT identity is strongly condemned, disclosing the stigmatized identity is equal to sentencing oneself to physical injury or murder (Pasha-Robinson, 2017).

Daniel, a 31-year-old transgender man, after so many years of being known to his parents as a lesbian woman, disclosed to them his transgender identity at the age of 27. By that time he had already been open to his other circles about his gender identity for quite some time. This is further evidence that Daniel, like Azat, did not consider his parents or his family environment to be safe enough for many years, because the family environment did not create any antecedent factors favorable to disclosure. Daniel remembers how he would cause domestic arguments and "dish throwing" during family quarrels just to force his parents to start calling him by his male name and refer to him as "he." Daniel's strategy would be to react only when his parents called him by his male name; otherwise he would completely ignore them. I consider this behavior to be Daniel's attempt to turn his family environment into a safe space, a securityscape where he could find comfort and feel like he belonged.

\section{Disclosing stigmatized identity as a securityscape to find meaning}

Another circumstance in which LGBT people consider identity disclosure a securityscape is when they search for the meaning of who they are in an attempt to find congruence between their public and private selves. Constrained by societal norms even in childhood, transgender children, for example, experience dissonance from others' perceptions of their gender identities and may seek to be perceived as their self-identified gender and be identified with it (rather than the one assigned to them at birth). Azat tells a story similar to that of the transgender girl depicted in the Belgian movie Ma vie en rose (Berliner \& Stapper, 1997), in which the main character of the movie, a seven-year-old transgender girl (assigned the male gender at birth), expresses her desire to be married to a neighbor's son but is devastated when her family and community react negatively. Likewise, Azat recollected how he declared his gender identity at a very young age, when he was six years old:

Well, the first time was when I was six years old. I told everybody that my name was Nikolay, and I used a name that was associated with a male name. And then I said I was not a girl, that I was a boy. My sister introduced me to ... took me to walk around with her friends and introduced me to them by my female name, right? And said that I was a girl. Then I started protesting and said I was a boy and that my name was Nikolay, that's it. And when we came home, my sister, actually my cousin, she shared the incident with my parents. My parents told me off, and said I was not a boy, I was a girl and that I could not call myself Nikolay.

This confusion, that even the closest people in their families could not appreciate their true identity, can distance LGBT children from their parents. Daniel also had a vivid memory from his childhood and early adolescence. Daniel never felt close to his parents as a child, although now he very much feels compassionate toward them: 
I did not approach my mother when I had my first menstruation. Prior to that, I had been playing around with a boy and kissing, and the very same day, the menstruation came. I was kind of surprised, thinking well, that was just a kiss. ... I could not tell my mother; she had already had lost my trust.

So Daniel always identified as a boy, and as early as when he was a little child, he would forget that he had a female body, but he was reminded as he grew into adolescence, when his breasts started showing and his first menstrual periods came. He describes how he felt extremely uncomfortable in his body and with his long hair. Daniel remembered this during the interview:

My hair was long until I turned 11, the length of my hair would almost reach my heels. So when my mom left to run errands one day, I went to a hair salon and had my hair chopped off all the way. Of course I was beaten for that by my mom, first for cutting it, and second because I had stolen money from her wallet to pay the hairdresser. My mother was even screaming, "Why didn't you at least take the hair with you?" (laughs). Well, because you can sell the hair and earn money, right? But I could care less.

When asked if he ever had imagined such consequences for having his hair cut, Daniel responded that just the mere thought of having a very short hairdo in his fantasies made him "feel so much happier." In this story, Daniel, like Azat, shared an example of how he started protesting against the gender that he was assigned and perceived by his community to be from birth.

Later in the interview, Daniel also shared a moment from his school years, when he confessed his love to his female classmate, which immediately became public. He painfully recalls the story of how he was embarrassed at first and had to skip school for a few days, but when he returned, Daniel publicly declared to his classmates that he still loved the girl as he cried to the entire class. He admits that, at the time, he did not know anything about transgender identity, so like Azat, he identified himself as a lesbian girl at the beginning. Azat's and Daniel's stories are examples of how transgender people attempt every possible effort to disclose their identities as a securityscape one way or another, even though in many instances during their childhood, they do not self-disclose their sexual and gender identities to others or the disclosure takes place through a series of deliberate and developmentally unaware actions.

In either case, whether LGBT people consider identity disclosure a securityscape or the opposite, when identity concealment is adopted as a securityscape, they search for meaning.

Unlike other people that I interviewed, Nurlan, a 24-year-old cisgender gay man, had a different background. He was raised in an orphanage and never knew his biological parents and relatives. Nurlan told an interesting story of his search for meaningfulness and electing to disclose his stigmatized identity as a gay boy in his early adolescence. When he was 12 years old, he approached the psychologist of the orphanage and told her about his "feeling that he was different." This is what he said:

Well, then I did not understand why I was going to see the psychologist. Then she explained something to me and afterwards told all the caregivers at the orphanage ... I was not sure she would disclose this to others, but I never had any bad thoughts when 
I decided to talk to the psychologist. I wanted to know what it is and why I am not like others. Why my personality is not like other children at the orphanage, like, you know, not as rough and something like that? Why, what, and etc.? Maybe it was because of my orientation ... Maybe that was the reason why I was soft.

After Nurlan's story, the psychologist appropriately explained to him that homosexuality was something normal and that it was fine the way he felt. Even so, she certainly broke ethical norms about confidentiality by telling the other caregivers about Nurlan's sexual orientation without his consent. As he grew older into adolescence, Nurlan's homosexual identity became central to his self-conception, and he started actively exploring his difference from others.

Finding meaning in one's own sexual orientation and gender identity is also gained by admiring others with the same stigmatized identity. One day, Zhenia, a 20 -year-old bisexual cisgender woman, and her mother went to a restaurant where a couple of lesbian girls were sitting across from their table. They were very open and visible, displaying their romantic relationship, which disgusted Zhenia's mother, who was horrified by the way the couple was acting. Zhenia, however, "admired" their courage despite the fact they were in a heteronormative environment. She shared:

I went to the bathroom and saw them there. I was staring at them; one of them had high winter boots and one of the shoes was half-way unbuttoned. I was staring at them and admiring how cool they were; they were courageous and kissing in public. Maybe because in my mind it was not a right thing for them to do, but they were courageous, doing it.

This incident hinted to Zhenia of the meaning she had been searching for as a bisexual person.

\section{Disclosing stigmatized identity as a securityscape in order to belong}

When Azat reached a stage in his life to decide whether to disclose as transgender or not, he started emotionally struggling with his gender identity. His barriers to disclosing as a transgender man were internalized transphobia (the centrality of his gender identity to his self-conception was distant) and living in an unwelcoming environment in which he wanted to disclose his transgender identity but didn't feel safe enough to do so. His internalized transphobia was a result of societal stigma and myths related to trans identities that he had been exposed to. He says he thought about disclosing for nearly a year, contemplating and thinking about it over and over. Azat claims that there were a lot of myths he believed in or he was told, for example, that "transgender people on hormones do not live long." He experienced cognitive dissonance about his imagined safe world versus the world he would live in as a masculine man if he ever decided to transition. For example, he would often think about, if he should become like a "real man," conforming to societal expectations of how a masculine man should look like in order to create a sense of security. Such thoughts horrified Azat and contradicted his values and beliefs.

Unlike cisgender gay, lesbian, and bisexual people, who have only one stigmatized identity in terms of their sexual orientation, due to the cisnormative and bi- 
nary world we live in, transgender people experience complex layers of stigmatized identities, as suggested by Zimman (2009): transgender people who undergo transition struggle with disclosure prior to transition, during transition, and post-transition, suggesting that the securityscapes of transgender people can dramatically change throughout their lives. This is what Azat recollected about his securityscape during his transition stage:

In general, when you [mentioned] Bishkek, as a whole, I consider it a safe place, because I fell in love with this city when I first came here. I started living here and it is still dear to my heart, its landscape, except for particular parts, for example, its transportation. That is when I had just disclosed, when my voice was not rough enough, I would get off the bus without saying the name of my bus stop, silently. Or I would get off where people got off the bus, even though it was not my stop. It was easier for me to walk a little distance than speaking.

This excerpt from Azat's story is evidence of how transgender people have to be continuously and consistently aware of their securityscapes in all dimensions spatial and psychosocial - compared to cisgender gay, lesbian and bisexual people, who can and do choose to pass as their apparent gender. Azat also shared a story about how his other securityscapes changed after transition in terms of different environments. Prior to his transition, Azat could go to a gynecologist and there would be no questions about who he was, and then he had to find a so-called "friendly" specialist so he did not have to go through explaining himself and justifying his existence. Azat shared an experience in a taxi as another example of how securityscapes changed for him after transition:

If, for example, before I took a cab, drivers would not usually talk to me. They would just greet me and that's it. And now that I appear to look more masculine they start conversations about sex, girls, what and how I should do it with girls. And even, for example, when I am short of money for five soms when paying for the cab, let's say my ride ended up costing 125 soms, and I only have 10 soms, the drivers usually say "that's OK, bro" and so on ... I don't know, some kind of a solidarity... If I measure it on a scale of one to five, one being the most safe and five being the least safe, I would measure a taxicab as "four" prior to transition and "one" after transition.

According to Azat, now that visually he is perceived as a man (Azat has facial hair and his voice is low), he admits he has new privileges he did not have before, one of which is demonstrated by his story with the taxicab above.

Zhenia was in the process of security-making for quite some time as a bisexual person. She elaborated on a story from her adolescence when she joined a women's soccer team so that she would meet other girls who shared the same securityscapes in her search for a feeling of belonging. Her mother's boyfriend brought Zhenia to join the soccer team and she remembers that moment:

So this dude, my mom's boyfriend, he saw this "boy" and asks, "Hey, boy, do you know where the girls' locker room is?" and the person walks in the locker room, showing us the way, and my mom's boyfriend cries [out], saying, "Hey, boy, don't go in there." Later it turned out that the boy was a transgender boy who had not transitioned but [had] a 
very boyish look and even low voice. So the person looks back at him and with a rude voice says that he is a girl... So, yes, I felt comfortable on the team.

Zhenia's story of her joining the girls' soccer team is an additional illustration of how LGBT people find securityscapes in their search for belonging and find LGBT others in an attempt to avoid isolation. A few weeks after the interview with Zhenia, I met her again for a follow-up interview in which we had a brief discussion about her activism in LGBT issues, and I saw a significant change that had happened since our last meeting. I asked her permission to include a summary from that discussion and she provided her consent. At that interview, I remember her telling a story in which she attended an international conference that discussed engagement and empowerment of youth and Zhenia was a LGBT youth representative at the event. She was telling how she was open about LGBT topics during the discussions, letting the audience know that if there are those uncomfortable with self-disclosing, they could approach her. This is how Zhenia was searching for meaning in her identity as a bisexual person, and her being open about her bisexuality at such platforms is evidence of voluntary identity disclosure as a securityscape, similar to Azat's activism as a transgender person. During the brief discussion I had with Zhenia, she made an interesting comment:

People do not understand that bisexuality is real. I hear a lot of them saying I am someone who has not made up her mind as to what I want in life. They do not see that my bisexuality is the same as their homosexuality or heterosexuality. I experience it similarly. So I have decided to start a movement for the visibility and acceptance of bisexuality as a real sexual orientation and raise awareness about it.

I consider this attempt as another way of Zhenia searches for belonging and adopts voluntary identity disclosure, indeed a proactive action, as a securityscape.

\section{Disclosing stigmatized identity as a securityscape to avoid fear of death}

Daniel shed light on very important stories from his life that explain how identity disclosure became a securityscape for him to protect his life. These particular stories relate to his experience as a transgender man in his work environment. Daniel shared stories about three job settings in which he proactively and voluntarily disclosed his gender identity. The first disclosure was when he was working as a waiter at a bar:

Mmm ... maybe it [the identity disclosure] was because of the boyish games that guys played; shouldn't a guy be strong and something like that? And the games are when boys fight with each other. I don't consider myself as strong, maybe that was the reason. And also to defend myself so they do not rely on me joining their games. That's it.

This story is very illustrative of identity disclosure as a securityscape. Daniel clearly named the reason he disclosed: in order to defend himself.

The second story follows:

At this job, I shared a flat with my colleagues. So in my own defense in case if ... The door of our bathroom would not shut completely. So I told them this and this, so if they 
accidentally happen to go in the bathroom and see me, so they do not get scared. But I immediately told them that if this bothers them, I was ready to move out.

Again, in this second story, Daniel uses the phrase "in my own defense" as if he were scared and predicting potential outcomes had he not disclosed his identity.

The third story is how he did not get a job because of having disclosed his identity:

There is an example, this was obviously a transphobia. I went to a well-known and foreign-run coffee shop in town; I found it from advertisements. I met with the administrator. I only wanted to be a dishwasher, so nobody [would pay] attention to me. So they said they need to see my ID, this and that. I handed her my passport and came out right away. Here you go, so there are no problems. I had been fed up concealing it. And she says, well, excuse me, I don't know, I will have to ask the bosses. So she did, called me back, and said they could not hire me.

This third example of considering identity disclosure as a securityscape in a job setting may not necessarily seem to be immediately motivated by an existential quest for a safe life and protecting oneself from physical injury (leading to death). However, this securityscape is critical because of the fear of losing a job, which helps sustain one's livelihood.

\section{Concealment of an invisible stigmatized identity as a securityscape}

The decision to conceal one's invisible stigmatized identity is the opposite of a proactive and voluntary disclosure of an invisible stigmatized identity as a securityscape. Concealment of stigmatized identity can be partial or complete, as when a person decides to completely conform to-or, in other words, integrate within-the norms and societal expectations of a heteronormative environment. In this case, an LGBT person usually gets used to living a so-called "double life" (their heteronormative life and their concealed and "secret" life) when they date other LGBT people, often for sex intercourse. Using partial concealment, however, LGBT people will identify themselves publicly as heterosexual but as LGBT in a very small social circle, which also mainly includes other LGBT people who have adopted partial concealment as a securityscape. When a complete concealment of identity is adopted as a securityscape, LGBT people do not even consider including other LGBT people in their intimate social circle.

Daniar, a cisgender gay man who refused to tell his age, lives in a more nonaffirming environment in the south of Kyrgyzstan, which historically has been considered a politically and socially conservative part of the country. Daniar never considered voluntary identity disclosure in Kyrgyzstan as a securityscape; however, away from his family, relatives, and community, in a foreign country where he spent his student years, disclosing his sexual orientation was a usual event whenever he found himself in a new social circle, although he mainly socialized in the LGBT community.

Daniar spent time in a European country where LGBT people were comparatively more accepted than in his community of origin. Upon return to the south of Kyrgyzstan, though, Daniar had to adjust his behavior and habits, and he could 
only feel free as an LGBT person in certain closed LGBT groups. According to him, there were around ten such groups, each with a leader. LGBT people (prior to the Internet era) would mainly socialize and date others within these groups, and their leaders were more financially sound individuals who could organize parties in rented apartments at their own expense. "There was even a competition among these groups," recollected Daniar, "for whose party is fancier." LGBT people in the south of Kyrgyzstan who considered partial concealment of their stigmatized identity as a securityscape regarded these groups and private apartment parties as environments where they could find safety and comfort and feel free with their identity. These closed environments were their securityscapes. This is what Daniar remembers from those closed parties:

In these parties I felt very free ... Of course, I could not behave like that on the street, like how I behaved in the parties. I was absolutely free in the parties. Even more free than I was abroad. I could openly express myself and my opinion. Not to argue or fight, but curse, behave like a woman, to be more precise.

Since identity disclosure was not considered a securityscape by Daniar and his peers, the need to find freedom still persisted and they found such freedom, although not to its full extent, as the concept of freedom is understood, in these groups and closed parties. This was another way of preventing the negative consequences of complete disclosure. It is important to note, though, that this description of freedom contradicts Daniar's perception of freedom when he lived abroad:

... Those were the happiest days in my life. I lived separately, away from my family. Nobody told me or directed me what to do... I was happy back in those days ... Of course I was free. Indeed very free. I was, let's say, like a bird to whom the entire world belonged.

By concealing their stigmatized identities, Daniar and other LGBT people in the south adopted different behavioral techniques, changing the way they talked and walked in the city. Daniar remembers a moment when he and his friends learned how to "behave manly" in an attempt to hide their "feminine features":

I saw how I walked; I saw how people walked. Of course we were different from the crowd and we could be easily spotted from the crowed. So we learned how to walk. We would watch ourselves walk in the mirror. Then we had telephones with cameras, which made everything much easier. We would film each other even when we would be walking on the streets. We saw how feminine we were; we did not want to change it, but we had to; we were forced by the circumstances. You think I need to rehearse for an hour in front of the mirror how to walk; I am not a top model after all! It was because of the safety, personal safety, because many things depended on it. That's why we had to change the way we walk and talk. I am sitting here talking to you; I can't be like this on the street. I can joke with my friends, be in drag, speak with high voice, but on the street I am a different person.

This excerpt from Daniar's story is perfect evidence of how people adopt identity concealment as a securityscape, with all the resulting consequences of artificially 
changing or constructing socially acceptable behavior in order to assimilate into a heteronormative environment.

In the case of Amantur, a 35-year-old bisexual cisgender man, he was in a heterosexual marriage but soon divorced. Amantur does not consider disclosing his stigmatized identity as an option at all. At the time of the interview, Amantur was dating a married man, who responded to his search for meaning and has become instrumental to Amantur in concealing his stigmatized identity as a securityscape.

Another way for Amantur to search for meaning in concealing his identity as a securityscape is his religious faith. Amantur identifies as a Muslim and has his own version of his faith. This is his reflection on his faith:

My religion is Islam, I believe in Islam, I consider myself a Muslim. Maybe not quite conforming to all the norms as an institutional religion... I practice Islam more spiritually, without framing myself with these doctrines ...

Amantur is not willing to freely and publicly embrace himself as a bisexual person, because he, very much like Daniar, is not ready to take the responsibility for the outcome of that identity disclosure, which is again also a well-framed strategy (considering identity concealment as a securityscape). Instead, Amantur relies on avoidance; this is how he describes it:

Life after death, it seems to me, is a continuation of the existence of our mind, our spirit... So much greenery, a forest before me. It seems like there is a house right next to the forest or trees. But there is a lot of greenery. It is raining and I imagine tropical trees of some kind and I smell the rain mixed with the scent of grass, with a fresh breeze. I am sitting [here] and transporting myself into that place.

This imagination could be Amantur's denial of and defense against the fear of death. I asked him to describe how he spent time with the boyfriend he was dating at the time of the interview. He had no doubt that in the eyes of the public, they were perceived as regular heterosexual friends. They did not display any signs of affection out in public and their romantic relationship was only behind closed doors. They usually rented an apartment where could they meet to spend romantic time and for sex intercourse:

... When we are out in public, we do not differ in any other way in general, I think; we do not attract any attention. It may be perceived as just two friends, as good heterosexual friends. This does not cause any suspicion. So he is comfortable and so am I. We never had any problems in deciding "oh, let's not go there." No, we are quite fine; we go wherever we want, we drink and smoke, eat, walk around, sometimes in a park. We socialize like normal people. Nothing peculiar.

In this response there are two key phrases I paid attention to: "... just two good heterosexual friends" and "...socialize like normal people." The adjectives "good" and "normal" are used when referring to heterosexual relationships, suggesting that Amantur might have moderately internalized biphobia. In his self-conception, his bisexual identity is still something negative compared to heterosexuals, who he 
describes as "good" and "normal." Therefore, another explanation why Amantur will not consider voluntary disclosure of his stigmatized identity as a securityscape is that his internalized biphobia is not allowing his bisexual identity to become central in his self-conception.

For both Daniar and Amantur, their sexual orientation is not quite central to their self-conceptions, and their antecedents to disclosure are very much framed by avoidance motivations. These avoidance motivations, in turn, may be justified by existential threats, such as fear of physical injury leading to permanent injury or death, and job loss leading to instability.

\section{Conclusion}

Although Cass's developmental model of identity disclosure by LGBT people was used along with other identity disclosure theories, I mainly lean toward the idea that identity disclosure is more complex than those theories, as shown in Figure 2. The developmental model was simply used to help readers understand what challenges and decisions LGBT people face in contemplating identity disclosure as a securityscape.

The research findings show how LGBT people consider proactive and voluntary disclosure of their stigmatized identity as a securityscape and how the disclosure event and its outcomes influence other securityscapes. For LGBT people, what were securityscapes prior to disclosure were no longer considered securityscapes afterwards.

To better understand identity disclosure as a securityscape, this study also compared the opposite securityscape: concealment of the stigmatized identity, which is also a reality of LGBT people in a nonaffirming societies. In Figure 2, considerations of voluntary identity disclosure are illustrated.

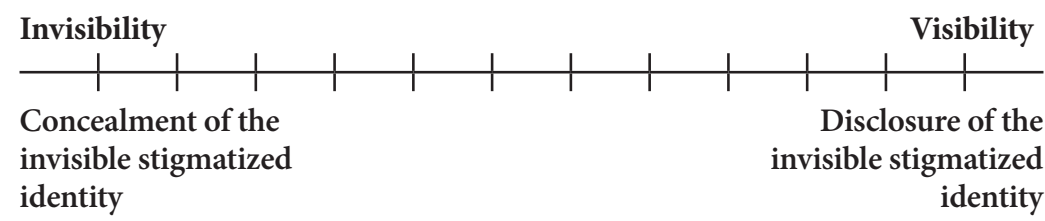

Figure 2. A contiuum of considerations of stigmatized identity disclosure as a securityscape

While Ragins, Chaudoir, \& Fisher $(2008,2010)$ discussed antecedents and approach and avoidance motives when explaining the disclosure of a stigmatized identity, and von Boemcken et al. (2016) explored the securityscapes of LGBT people from anthropological perspectives, my research found that identity disclosure as a securityscape should be considered on a continuum, with identity concealment as a securityscape on one side and complete identity disclosure as a securityscape on the other. In both cases, whether LGBT people decide to adopt identity disclosure or conceal their stigmatized identity as securityscapes, the centrality of their sexual orientations and gender identities to their self-conceptions plays a significant role. However, whether the stigmatized identity is central to their self-conception or not is dictated by how LGBT people decide to cope with the givens of their existence. 
If an LGBT person believes that for them it is easier to avoid the fear of death by disclosing their stigmatized identity, for them identity disclosure will be a securityscape. On the contrary, if an LGBT person considers that identity disclosure will result in physical injury and potentially lead to death, they will consider concealing the stigmatized identity as a securityscape. (The fear of death here is provided as an example, and considerations can revolve around other givens of existence as well.) Figure 2 graphically illustrates the extent to which disclosure or concealment of stigmatized identity (from complete invisibility to a wide public visibility) is considered as securityscape by LGBT people. LGBT people may also consider partial identity disclosure a securityscape within certain circles of socialization, i.e., spatial and psychosocial dimensions.

In a family environment, parents usually are not considered confidants for the primary stages of disclosure, at least not for cisgender gay, lesbian, and bisexual people in a nonaffirming society. For transgender people, however, family may play a different role in the disclosure process because for transgender people, there are also nonverbal identity disclosure strategies. For them, disclosure may not necessarily be a proactive verbal disclosure, as was evidenced by Zimman (2009); at certain points verbal disclosure will transform into nonverbal disclosure and vice versa. At an early age, transgender people may nonverbally display behaviors of a gender identity they identify with without consciously and deliberately verbalizing it. Moreover, the disclosure of transgender identity may be even further complicated in some instances, with two entirely different stages of disclosure, as some respondents have experienced: initially as homosexual people and only later as transgender people; in other instances, immediate disclosure as a transgender person is also possible. There are also other transgender people who attempt to forget their past after transition and completely integrate into the heteronormative world if they identify as heterosexuals.

For Daniel, the transgender man, Kyrgyzstan has failed to provide a safe and decent life even after his disclosure event, and therefore he does not consider his home country to be able to provide any favorable conditions for him to live a free, socially fulfilling life in an environment that would defend him from physical injury and provide meaning to his life (existential givens). Ultimately, the goal for Daniel is to leave Kyrgyzstan, his current spatial dimension, and relocate to another country where his identity is more accepted.

Involuntary disclosure of a stigmatized identity (also called "outing") cannot be considered a securityscape. However, this definitely has an impact on the state of other securityscapes prior to and after such an involuntary disclosure event.

And finally, one effective way of advocating for LGBT rights in a nonaffirming society is to raise public awareness through educating the population and organizing nonviolent protests and demonstrations (Carroll, 2010), which is nearly impossible if LGBT people lean toward complete or partial concealment of their stigmatized identity as a securityscape. Therefore, from a sociopolitical perspective of advocating for LGBT rights, it might be important that more and more LGBT people start considering identity disclosure as a securityscape, as in the case of Azat, for example. This would be plausible if antecedents develop that allow LGBT people to consider their sexual orientation and gender identity as central to their self-conceptions. 


\section{Limitations}

The concept of securityscapes from a psychological perspective is an underexplored topic, and very little theory is available that could back up some of the findings of the research. Securityscapes have mainly been considered from conventional security paradigm and to a lesser extent from a psychological human-agency paradigm, and there is still a significant number of research questions that need more investigation.

Parents of LGBT children may experience different securityscapes in addition to dealing with their children's identity disclosure. Parents need to consider whether the fact that their children have disclosed their stigmatized identity can be a securityscape for them, especially when transgender children decide to go through transition, which is visible to relatives and friends. Similarly, siblings may face the same challenges as parents. Research could be launched to explore the securityscapes of parents and siblings of LGBT people, as well as their friends.

The geography of the research was limited to a relatively conservative society and therefore the responses given by respondents may be limited to the environment they live in, whereas there are assumptions that identity disclosure as a securityscape could have other, different approach and avoidance motivations as antecedents in societies with more open attitudes and perceptions of LGBT people.

The findings of this research, however, provide scholars with an additional theoretical framework to understand the emerging concept of securityscapes. This study enriches the research about the disclosure of stigmatized identities, and particularly in conceptualizing the strategies of identity disclosure by LGBT people.

\section{Acknowledgments}

I would like to thank my professor, Dr. Nina Bagdasarova of the American University of Central Asia (AUCA), for her guidance. She exposed me to the concept of securityscapes and suggested researching identity disclosure within the concept of securityscapes. Also thanks to my other professors, Dr. Kim, Dr. Kosterina, Dr. Molchanova, Dr. Murdock, Dr. Haefliger, and Dr. Mamatova, for their continuous academic support throughout my studies.

I would like to also thank participants of the research for their eagerness to contribute to enriching the pool of studies on LGBT topics, and for their committed participation in the interviews.

Special acknowledgement goes to my father, John H. Krob, Esq., who has never quit believing in me and continues motivating me in every step I make forward. Thank you, Dad, for showing your trust in me!

\section{References}

American Psychological Association. (2011). Answers to your questions about transgender people, gender identity, and gender expression. Retrieved from http://www.apa.org/topics/ lgbt/ transgender.aspx

American Psychological Association. (2015). Key Terms and concepts in understanding gender diversity and sexual orientation among students. Retrieved from https://www.apa.org/pi/ lgbt/programs/safe-supportive/lgbt/key-terms.pdf 
Annual news-release on LGBT situation in Kyrgyzstan. (2017, February 5). Kyrgyz Indigo Annual News-release.

Appadurai, A. (1996). Modernity at Large: Cultural Dimensions of Globalization (Vol. 1). University of Minnesota Press.

Barnes, D.M., \& Meyer, I.H. (2012). Religious affiliation, internalized homophobia, and mental health in lesbians, gay men, and bisexuals. American Journal Of Orthopsychiatry, 82(4), 505-515. doi: 10.1111/j.1939-0025.2012.01185.x

Berliner, A. (Director), \& Berliner, A., \& Stappen, C.V. (1997). Ma vie en rose [Motion Picture]. Belgium: Sony Pictures Classics. Retrieved from http://www.imdb.com/title/tt0119590/

Bilodeau, B.L., \& Renn, K.A. (2005). Analysis of LGBT identity development models and implications for practice. New Directions for Student Services, 111, 25-39. doi: 10.1002/ss.171

Bubandt, N. (2005). Vernacular security: The politics of feeling safe in global, national and local worlds. Security Dialogue, 36(3), 271-296. doi: 10.1177/0967010605057015

Carroll, A. (2010). Make it work: Six steps to effective LGBT human rights advocacy. Belgium, Brussels.

Cass, V.C. (1979). Homosexual identity formation: A theoretical model. Journal of Homosexuality, 4(8), 219-235. doi: 10.1300/J082v04n03_01

Chaudoir, S.R., \& Fisher, J.D. (2010). The disclosure processes model: Understanding disclosure decision-making and post-disclosure outcomes among people living with a concealable stigmatized identity. Psychological Bulletin, 136(2), 236-256. doi: 10.1037/a0018193

Compilation prepared by the Office of the United Nations High Commissioner for Human Rights in accordance with paragraph 15 (b) of the annex to Human Rights Council resolution 5/1 and paragraph 5 of the annex to Council resolution 16/21 (Rep. No. A/HRC/ WG.6/21/KGZ/2). (2014, November 12). Retrieved from https://www.upr-info.org/sites/ default/files/document/kyrgyzstan/session_21_-_january_2015/a_hrc_wg.6_21_kgz_2_e. pdf

Costa, P.A., Pereira, H., \& Leal, I. (2013). Internalized homonegativity, disclosure, and acceptance of sexual orientation in a sample of portuguese gay and bisexual men, and lesbian and bisexual women. Journal of Bisexuality, 13(2), 229-244. doi: 10.1080/15299716. 2013.782481

Crawford, A., \& Hutchinson, S. (2015). Mapping the contours of 'everyday security': Time, space and emotion. British Journal of Criminology. doi: 10.1093/bjc/azv121

Dunn, K. (2015). Chapter 6: Interviewing. In Qualitative research methods in human geography (4th ed., pp. 101-138). Oxford, UK: Oxford University Press.

Frost, D.M., \& Meyer, I.H. (2009). Internalized homophobia and relationship quality among lesbians, gay men, and bisexuals. Journal of Counseling Psychology, 56(1), 97-109. doi: 10.1037/ a0012844

Goldstein, N. (2015). Eight questions of faith: Biblical challenges that guide and ground our lives. University of Nebraska Press.

Human Rights Watch. (2014). "They said we deserved this". Police violence against gay and bisexual men in kyrgyzstan (Rep.). USA: Human Rights Watch. Retrieved from https://www.hrw. org/report/2014/01/28/they-said-we-deserved/police-violence-against-gay-and-bisexualmen-kyrgyzstan

Wilson, L., \& Bakker, L. (2016). Cutting off the king's head: Security and normative order beyond the state. Conflict, Security \& Development, 16(4), 289-300, doi: 10.1080/14678802.2016.1200311

Lemanski, C. (2012). Everyday human (in)security: Rescaling for the Southern city. Security Dialogue, 43(1), 61-78. doi: 10.1177/0967010611430435

Parfyonova, O. (2010). Vozmozhen li kaminaut v Rossii? Stsenarii otrkytia lesbiiskoi identichnosti [Is coming out possible in Russia? Scenarios of disclosing lesbian identity]. In Prak- 
tiki i identichnosti, gendernoe ustroistvo [Practices and identities, gender construct] (1st ed., pp. 296-322). Saint Petersburg, Russia: European University in Saint Petersburg.

Pasha-Robinson, L. (2017, May 09). Gay teen 'pushed to death from Chechen balcony' as Ramzan Kadyrov rejects reports of homosexual 'purge'. Retrieved from http://www.independent.co.uk/news/world/europe/gay-teen-chechnya-balcony-pushed-death-leader-ramzankadyrov-purge-homosexuals-torture-detain-murder-a7725526.html

Rogers, C.R., \& Kramer, P.D. (1995). On becoming a person: A therapist's view of psychotherapy. Boston, US: Houghton Mifflin Harcourt.

UNDP. (1994). Human Development Report (Rep.). New York: Oxford University Press. Retrieved from http://hdr.undp.org/sites/default/files/reports/255/hdr_1994_en_complete_ nostats.pdf

University of Houston. (n.d.). Reducing Heteronormativity. Retrieved from http://www.uh.edu/ lgbtq/resources/pdf/heteronormativity.pdf

Von Boemcken, Boboyorov, H. M., Bagdasarova, N., \& Sulaimanov, J. (2016). Working paper: Existential danger in everyday life [Securityscapes of Minority Groups in Urban Spaces of Kyrgyzstan]. Bishkek: American University of Central Asia.

Yalom, I.D. (1980). Existential Psychotherapy. New York: Basic Books.

Yalom, I.D. (2013). Love's Executioner and other tales of psychotherapy (3rd ed.). London, UK: Penguin Books.

Zalutskii, A. (2017, February 3). Otkrytyi mikrofon: Pavel Zalutskii - Ya gay iz serial. [Open microphone: Pavel Zalutskii - I am a gay from series]. Retrieved from https://rutube.ru/ video/f47e4843e5ae606e03dee3f202a3a514/

Zimman, L. (2009). The other kind of coming out: Transgender people and the coming out narrative genre. Gender and Language, 3(1), 53-80. doi:10.1558/genl.v3i1.53 